Review

\title{
From Light to Sound: Photoacoustic and Ultrasound Imaging in Fundamental Research of Alzheimer's Disease
}

Yuqi Tang ${ }^{1}$, Xuejun Qian ${ }^{2,3}$, Darrin J. Lee ${ }^{4}$, Qifa Zhou ${ }^{2,3,}{ }^{*}$, Junjie Yao ${ }^{1, *}$

1. Department of Biomedical Engineering, Duke University, Durham, NC, USA; E-Mails: yuqi.tang@duke.edu; junjie.yao@duke.edu

2. Department of Biomedical Engineering, University of Southern California, Los Angeles, CA, USA; E-Mails: xuejunqi@usc.edu; qifazhou@usc.edu

3. USC Roski Eye institute, University of Southern California, Los Angeles, CA, USA

4. Department of Neurological Surgery, University of Southern California, Los Angeles, CA, USA; EMail: darrin.lee@med.usc.edu

* Correspondence: Qifa Zhou and Junjie Yao; E-Mails: qifazhou@usc.edu; junjie.yao@duke.edu

Academic Editors: Golam Sharoar and Bart Ellenbroek

Special Issue: Alzheimer's Disease Research

\section{OBM Neurobiology}

2020, volume 4, issue 2

doi:10.21926/obm.neurobiol.2002056
Received: October 24, 2019

Accepted: April 15, 2020

Published: April 30, 2020

\begin{abstract}
Alzheimer's disease $(A D)$ causes severe cognitive dysfunction and has long been studied for the underlining physiological and pathological mechanisms. Several biomedical imaging modalities have been applied, including MRI, PET, and high-resolution optical microscopy, for research purposes. However, there is still a strong need for imaging tools that can provide high spatiotemporal resolutions with relatively deep penetration to enhance our understanding of $A D$ pathology and monitor treatment progress in fundamental research. Photoacoustic (PA) imaging and ultrasound (US) imaging can potentially address these unmet needs in $A D$ research. PA imaging provides functional information with endogenous and/or exogenous contrast, while US imaging provides structural information. Recent studies have demonstrated the ability to monitor physiological parameters in small-animal brains with PA and US imaging as well as the feasibility of using US imaging as a therapeutic tool for AD. This
\end{abstract}

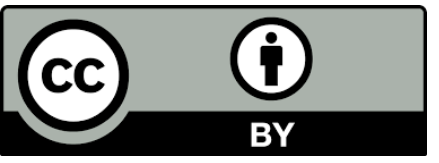

(C) 2020 by the author. This is an open access article distributed under the conditions of the Creative Commons by Attribution License, which permits unrestricted use, distribution, and reproduction in any medium or format, provided the original work is correctly cited. 
concise review aims to introduce recent advances in AD research using PA and US imaging, provide the fundamentals, and discuss the potentials and challenges for future advances.

\section{Keywords}

Photoacoustic imaging; ultrasound imaging; Alzheimer's disease; brain imaging

\section{Introduction}

Alzheimer's disease (AD) is a chronic and deadly neurodegenerative disease that causes $60-70 \%$ of cases of dementia. An estimated 5.8 million Americans of all ages suffered from Alzheimer's dementia in 2019, and as the population ages, the number is projected to reach 8.5 million [1]. The deposition of senile plaques and the formation of neurofibrillary tangles are the two pathognomonic, histopathological findings found in AD [2-4]. Senile plaques consist of a central core of amyloid- $\beta(A \beta)$, a 4-kD peptide, surrounded by abnormally configured neuronal processes or neurites. Though debatable, the amyloid cascade hypothesis suggests that the aggregation of misfolded $A \beta$ forms insoluble plaques [5]. The neurofibrillary tangle consists of an abnormal accumulation of aberrantly phosphorylated tau within the perikaryal cytoplasm of certain neurons [6]. The loss of synaptic components significantly impacts cognitive function, which represents another morphological alteration [6]. The classification of AD has been divided into three phases $[7,8]$. In the presymptomatic phase, the patient is cognitively normal but with evidence of amyloid deposition and/or neuropathological changes. As the deposition and neurodegeneration worsen, the patient progresses through the symptomatic prodromal phase, which is characterized by amnestic mild cognitive impairment $(\mathrm{MCl})$. In the third phase, widespread cognitive deficits in multiple domains occur and interfere with the patient's daily living activities, indicating that the disability threshold is reached and traditional diagnostic criteria for probable AD are met. However, it is often difficult to distinguish between $A D$, especially at its early stage, and nor mal aging due to similarities in pathology and cognitive decline [9]. In addition, it is common for AD to coexist with other brain disease processes such as infarction or Parkinson's disease-related lesions [10].

Several medical imaging approaches have been used not only to diagnose early stage AD but also to better understand $A D$ pathology, including magnetic resonance imaging (MRI), positron emission tomography (PET), and high-resolution optical methods. The detection of $A D$ is achieved either through direct imaging of biomarkers such as $A \beta$ and phosphorylated tau with the aid of exogenous contrast agents or through indirect identification of characteristic structural and functional cerebral alterations. Atrophy is a precursor of progression from $M C l$ to $A D$, which allows structural MRI to be used for AD diagnosis by estimating tissue damage or loss in characteristically vulnerable brain regions such as hippocampus and entorhinal cortex.

In addition to structural brain atrophy, cerebrovascular function is profoundly altered due to reduction in cerebral microvessels, flattening of endothelial cells, and degeneration of smooth muscle cells [11]. In $A D$, resting cerebral blood flow (CBF) is reduced and an activation-induced increase in CBF is attenuated. These abnormalities can be detected with functional MRI (fMRI), which can measure local blood volume (perfusion MRI) and blood oxygen-level dependent (BOLD) signals. Perfusion MRI is used less frequently due to its low sensitivity. BOLD fMRI relies on the 
magnetization difference between oxygenated hemoglobin $\left(\mathrm{HbO}_{2}\right)$ and deoxygenated hemoglobin $(\mathrm{HbR})$, has a relatively high spatial resolution (approximately 1-10 $\mathrm{mm}$ ), and has an imaging acquisition speed that ranges from several seconds to hundreds of milliseconds (echo-volumar imaging) depending the type of excitation and acquisition sequence $[12,13]$. BOLD $f M R I$ is further applied in clinical settings in two ways: task-based fMRI and resting-state fMRI. The former studies the patterns of activation or deactivation of a subject during the performance of repeated tasks. However, due to an extensive participation requirement that may be difficult for $A D$ patients, resting-state $\mathrm{fMRI}$, which studies spontaneous low-frequency fluctuation in BOLD signals [14], has recently become more utilized. Nevertheless, MRI is expensive and has low mobility. Even with high-resolution $\mathrm{fMRI}$, it is difficult to visualize individual brain vessels.

PET also plays a leading role in the early detection of AD. PET employs 2-[ $\left.{ }^{18} \mathrm{~F}\right]-$ fluoro-e-deoxy-Dglucose (FDG) to measure synaptic functions and density by providing quantitative or qualitative estimates of the cerebral metabolic rate of glucose (CMRgIc) [15-17]. Though FDG-PET is highly sensitive, it lacks disease specificity as a reduction in CMRglc is also found in many other dementias. To overcome this limitation, $A \beta$ PET radiotracers such as Pittsburgh Compound $B$ (PIB) and 2-(1-96-(2- ${ }^{18} \mathrm{~F}$-fluoroethyl)(methyl)amino)2-naphthyl)ethyldene) malononitrile $\left({ }^{18} \mathrm{~F}-\mathrm{FDDNP}\right)$ are used to improve diagnostic specificity and accuracy $[18,19]$. The major limitations of PET are its ionizing radiation, low temporal resolution (5-10 seconds for clinical dynamic PET), and high system/scan cost $[20,21]$.

High-resolution optical methods such as optical coherence tomography (OCT) and two-photon microscopy (TPM) have also been explored in AD studies and diagnostics. Clinical records and histologic studies show strong evidence of anterior visual path impairment in AD patients. By measuring peripapillary retinal nerve fiber layer thickness, macular thickness, and other retinal parameters, OCT can be used to distinguish AD from normal aging [22, 23]. TPM can provide direct imaging of $A \beta$ with high resolution, yet its penetration is bound by the optical diffusion limit ( $~ 1$ $\mathrm{mm})$, thus limiting its application to small animal studies [24, 25].

Great advancements have occurred in $A D$ diagnostics and research with the support of the aforementioned biomedical imaging modalities, but major challenges remain unsolved. Photoacoustic (PA) imaging and ultrasound (US) imaging are two modalities that have relatively high device portability and zero ionizing radiation as well as relatively high spatiotemporal resolution and deep penetration (several centimeters) $[26,27]$. In this review paper, we will introduce the imaging formation principles of PA and US imaging, describe the recent developments and applications for $A D$ research, diagnosis, and treatment, and discuss the potential to combine PA and US modalities for future AD applications.

\subsection{Photoacoustic Imaging}

PA imaging, a hybrid imaging modality that combines light and sound, can bridge the resolution and penetration depth gaps in brain imaging [26]. In PA imaging, pulsed laser light illuminates the target, and the incident photons are subsequently absorbed by the chromophores in the target, leading to a transient increase in temperature. The local temperature rise induces a local pressure increase, resulting in the emission of broadband (approximately tens of $\mathrm{MHz}$ ), low-amplitude (typically less than $10 \mathrm{kPa}$ ) ultrasonic waves [26]. As acoustic waves generally undergo less scattering and attenuation in soft tissues than light, PA imaging can form high-resolution images in 
both ballistic and diffusive regimes [27]. Its high-resolution, label-free imaging nature provides PA imaging with great utility in the study of neurovascular coupling, which refers to the relationship between neuronal activity and hemodynamics [28].

\section{Configurations of Conventional Photoacoustic Imaging Systems}

Based on the configurations of optical illumination and ultrasonic detection, PA imaging can be further classified into two major types: photoacoustic microscopy (PAM) and photoacoustic computed tomography (PACT). PAM uses tightly or weakly focused light for excitation and a focused single-element ultrasonic transducer for direct image formation through point by point scanning $[29,30]$. PAM can provide spatial resolution ranging from sub-micrometer to submillimeter with a maximum penetration ranging from a few hundred micrometers to a few millimeters [30]. PAM can be further classified into optical-resolution PAM (OR-PAM) and acoustical-resolution PAM (AR-PAM). In OR-PAM, the light is tightly focused and the light spot is smaller than the ultrasonic focus. The transverse resolution, therefore, is determined by the light focal spot size, and the penetration is limited to $\sim 1 \mathrm{~mm}$ in soft tissue [31]. In AR-PAM, the light is loosely focused and ultrasonic detection is tightly focused; therefore, relatively high resolution can be achieved within the quasidiffusive regime (a few optical transport mean free paths) [31, 32]. In PACT, homogenized illumination is provided to the entire region of interest in the diffusive regime, and the generated ultrasonic signals are acquired by an ultrasonic transducer array and then reconstructed to form the image by an inverse algorithm [29]. The spatial resolution of PACT is mainly limited by the acoustic diffraction limit as well as the directionality of the detector elements [33]. Currently, for small animal brain imaging, a full-ring transducer array with a low central frequency $(5 \mathrm{MHz})$ or a linear transducer array with a high central frequency $(21 \mathrm{MHz})$ is used to provide spatial resolution ranging from tens of micrometers to sub-millimeters [34-36]. Hence, with different system configurations, PAM has been mainly utilized for high spatialresolution imaging in the cortex region, and PACT has been applied for deep brain imaging with compromised spatial resolutions (Figure 1).

A

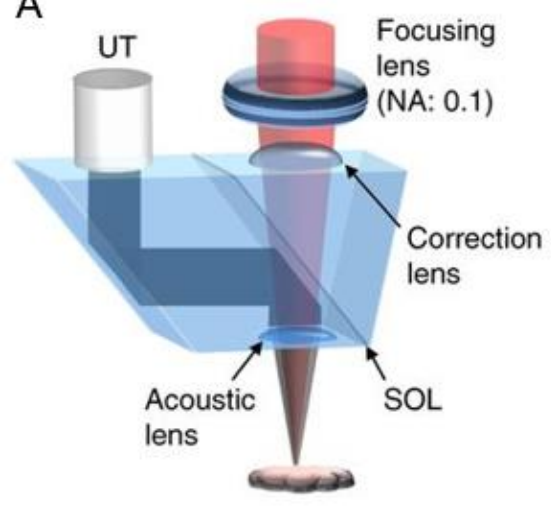

B

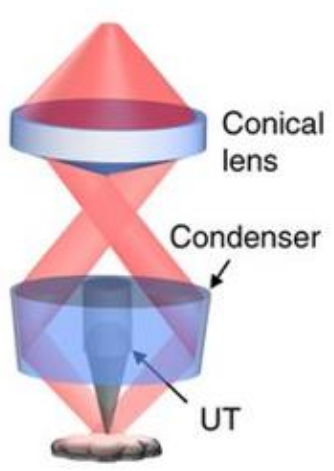

C

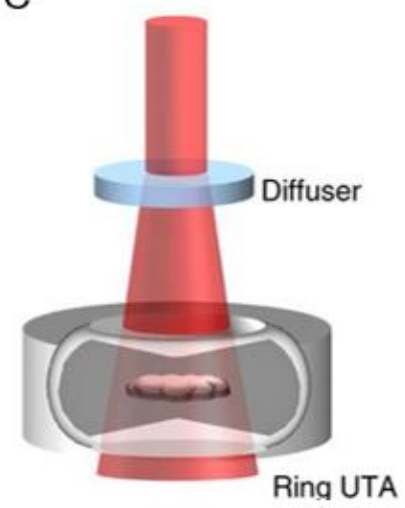

Figure 1 Schematics for various photoacoustic imaging systems. (A) Reflection-mode OR-PAM system with an optical-acoustic combiner that transmits light and reflects sound. SOL, silicone oil layer; UT, ultrasonic transducer. (B) Dark-field AR-PAM system with excitation light only weakly focused. (C) PACT system with a full-ring transducer and widefield illumination from top. UTA, ultrasonic transducer array [37]. 
A wide variety of endogenous and exogenous chromophores have been used in PAl for structural, functional, and molecular imaging. Among all endogenous chromophores, hemoglobin is one of the most commonly used due to the strong optical absorption of both oxygenated hemoglobin $\left(\mathrm{HbO}_{2}\right)$ and deoxygenated hemoglobin $(\mathrm{HbR})$ at wavelengths in the visible and nearinfrared spectral range $[26,29]$. Such strong absorption allows PAI to not only visualize bloodperfused vasculature with high contrast but also estimate blood oxygenation $\left(\mathrm{sO}_{2}\right)$, which is defined as:

$$
\mathrm{sO}_{2}=\frac{\mathrm{C}_{\mathrm{HbO}_{2}}}{\mathrm{C}_{\mathrm{HbO}_{2}}+C_{\mathrm{HbR}}} \times 100 \%
$$

where $\mathrm{C}_{\mathrm{HbO2}}$ and $\mathrm{C}_{\mathrm{HbR}}$ stand for concentration of $\mathrm{HbO}_{2}$ and $\mathrm{HbR}$ respectively. In $\mathrm{PAl}, \mathrm{sO}_{2}$ measurement is achieved through multispectral imaging, where laser excitation is provided at multiple wavelengths and $\mathrm{C}_{\mathrm{HbO2}}$ and $\mathrm{C}_{\mathrm{HbR}}$ are estimated using different methods [38]. $\mathrm{sO}_{2}$ normally ranges from $95 \%$ to $100 \%$ in arteries and from $60 \%$ to $80 \%$ in veins [39]. However, some disease processes may alter the balance of oxygen delivery and consumption and thus change the $\mathrm{sO}_{2}$. Therefore, multispectral PAl of $\mathrm{sO}_{2}$ has potential use in disease screening, diagnosis, and therapy monitoring.

The differences between PA imaging and BOLD FMRI, both of which have signals relevant to blood oxygenation, are noteworthy. The contrast for BOLD $\mathrm{FMRI}$, fundamentally different from that of PA imaging, arises from the change in the local 'magnetic susceptibility'; $\mathrm{HbO}_{2}$ is diamagnetic and $\mathrm{HbR}$ is paramagnetic. The deoxygenation of blood increases the magnetic susceptibility of blood vessels relative to surrounding brain tissue, leading to a signal loss around the blood vessel, and vice versa $[40,41]$. Therefore, $\mathrm{BOLD}$ signals are sensitive only to $\mathrm{HbO}_{2}$. Moreover, $\mathrm{BOLD} f M R I$ has intrinsically low signal-to-noise ratio (SNR) and contrast-to-noise ratio (CNR) and thus requires repetitive stimuli in order to decrease variance in the BOLD signals [40]. In contrast, as $\mathrm{HbO}_{2}$ and $\mathrm{HbR}$ have absorption coefficients that are at least 100 times higher than other endogenous absorbers at visible and near-infrared wavelengths, PAI has much better SNR and CNR than BOLD $\mathrm{fMRI}$ and allows more direct measurement of relative concentrations of both $\mathrm{HbO}_{2}$ and $\mathrm{HbR}$.

\section{Photoacoustic Imaging in AD}

Hu et al. used OR-PAM to image amyloid plaques in AD mice models (Figure 2A) [42]. Congo red dye was injected through cisterna magna into APP/PS1 mice to label $A \beta$. An open-skull cranial window was created, and dual-wavelength OR-PAM images were acquired at $570 \mathrm{~nm}$ and $523 \mathrm{~nm}$ to differentiate between hemoglobin and Congo red-labeled amyloid plaques. The absorption coefficient of Congo red at $523 \mathrm{~nm}$ is approximately six times higher than at $570 \mathrm{~nm}$, and for hemoglobin the absorption coefficients only differ 1.4-fold [43]. The optical coefficients $\mathrm{HbO}_{2}$ and $\mathrm{HbR}$ are nearly equal at both wavelengths, and thus the blood PA signals reflect the total hemoglobin concentration regardless of the blood oxygenation level. In addition to OR-PAM imaging, multiphoton microscopy was used to acquire fluorescent images of the same region for comparison and validation of the plaque imaging capability of OR-PAM (Figure 2B and 2C). The acquired PA image at $523 \mathrm{~nm}$ was first linearly scaled to equalize the blood vessel signal taken at $570 \mathrm{~nm}$ and then subtracted pixel-wise to eliminate the blood signal and isolate the Congo redlabeled plaques (Figure 2D-F). A few small plaques were not directly detected by the OR-PAM system due to limited SNR, non-optimized excitation wavelength for Congo red, and interference 
from strong blood absorption. However, as proposed by $\mathrm{Hu}$ et al., the problem can be partially addressed by changing one optical wavelength to $500-510 \mathrm{~nm}$, which is the absorption peak of Congo red and a local absorption minimum of hemoglobin [42].
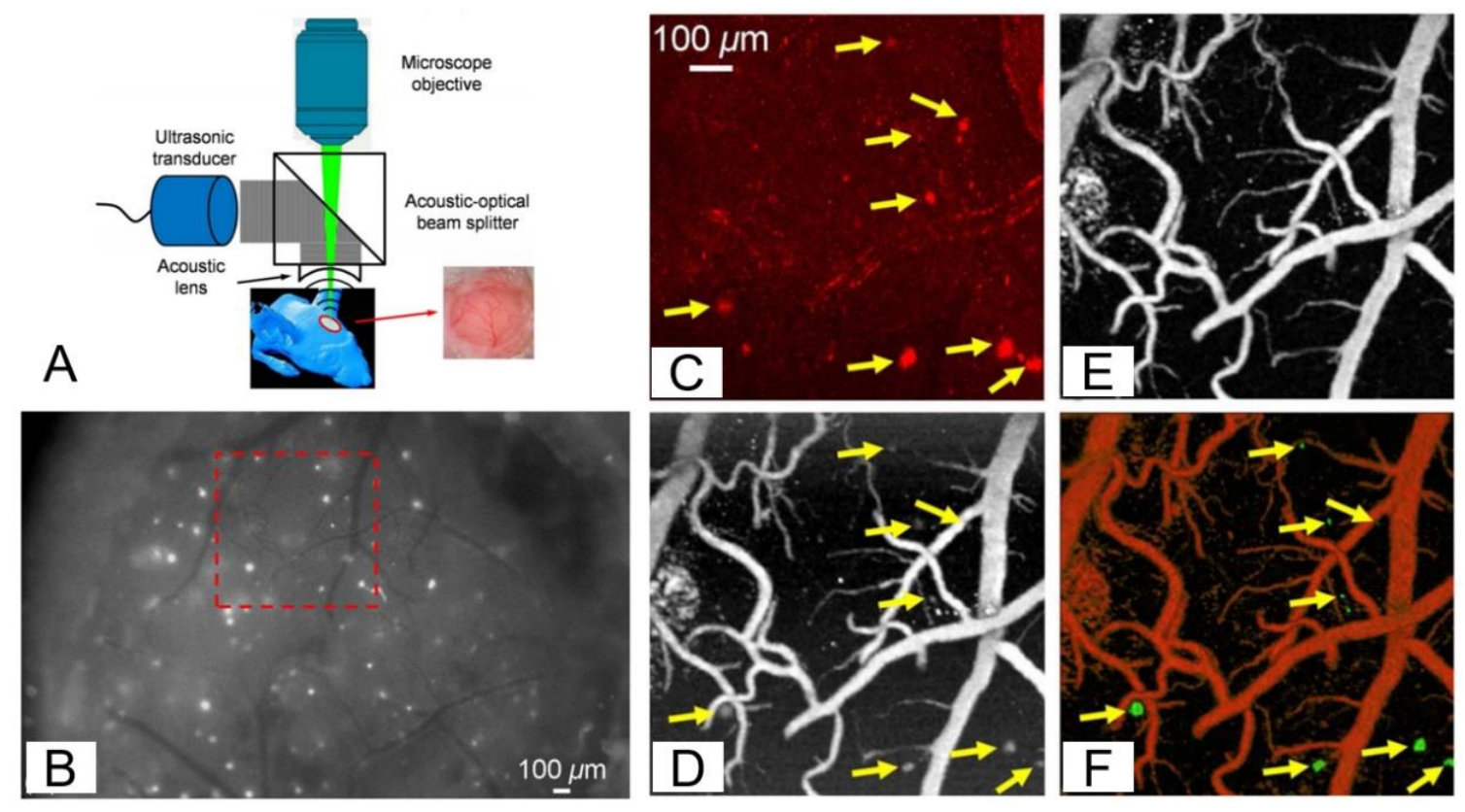

Figure 2 In vivo brain imaging of a Congo red-injected 10-month-old APP/PSI mouse through a cranial window. (A) System schematic of the optical-resolution photoacoustic microscope for amyloid plaque imaging. (B) Conventional fluorescence microscopy imaging of exposed cortical region through the cranial window. The region of interest is labeled with a red-dashed box. (C) Multiphoton microscopy image of the region of interest; excitation at $800 \mathrm{~nm}$. (D) OR-PAM image at $523 \mathrm{~nm}$. (E) OR-PAM image at 570 $\mathrm{nm}$. (F) Processed and labeled OR-PAM image (plaques colored green, blood vessels colored red). Arrows indicate plaques. (reproduced from [42], OSA publishing, all rights reserved)

PACT has been used in combination with perfusion MRI to demonstrate the cortical hypofusion and reduced cerebral metabolic rate of oxygen $\left(\mathrm{CMRO}_{2}\right)$ in the $\operatorname{arcA} \beta$ mouse model [44]. Quantification of the oxygen saturation $\left(\mathrm{SO}_{2}\right)$ and brain oxygen extraction fraction (OEF), together with measured CBF from perfusion MRI, allows the elucidation of brain functional physiology and thus the study of neurological disorders [45]. In their PACT imaging study, Ni et al. used five wavelengths $(715,730,760,800$, and $850 \mathrm{~nm})$ to estimate arterial oxygenation saturation $\left(\mathrm{s}_{\mathrm{a}} \mathrm{O}_{2}\right)$ in the middle cerebral arterial (MCA), venous oxygen saturation $\left(\mathrm{s}_{\mathrm{v}} \mathrm{O}_{2}\right)$ in the superior sagittal sinus (SSS), and cortical vessel oxygenation as an approximation for cortical tissue oxygenation $\left(\mathrm{s}_{\mathrm{t}} \mathrm{O}_{2}\right)$ [44]. PA imaging and perfusion MRI images were acquired on wild-type and transgenic arcA $\beta$ mice at 6- and 24-mo old. A linear unmixing algorithm was applied to the acquired PA data at all five wavelengths to resolve signals from $\mathrm{HbO}_{2}$ and $\mathrm{HbR}$. Subsequently, $\mathrm{s}_{\mathrm{a}} \mathrm{O}_{2}, \mathrm{~s}_{\mathrm{v}} \mathrm{O}_{2}, \mathrm{~s}_{\mathrm{t}} \mathrm{O}_{2}$ were calculated and the OEF values were obtained as

$$
\mathrm{OEF}=\frac{\left(s_{a} O_{2}-s_{v} O_{2}\right)}{s_{a} O_{2}}
$$

The hyperoxia induced change in tissue oxygenation was defined as 


$$
\Delta \mathrm{s}_{\mathrm{i}} \mathrm{O}_{2}=\overline{\text { Hyperoxia } \mathrm{s}_{1} \mathrm{O}_{2}} \text { - } \overline{\text { Hypoxia } \mathrm{s}_{1} \mathrm{O}_{2}} .
$$

Based on Fick's principle, $\mathrm{CMRO}_{2}$ can be derived from arteriovenous oxygen gradient with the formula

$$
\mathrm{CMRO}_{2}=\mathrm{CBF} *\left(\mathrm{~S}_{a} \mathrm{O}_{2}-\mathrm{S}_{v} \mathrm{O}_{2}\right) * \mathrm{C}_{a^{\prime}}
$$

where $\mathrm{C}_{\mathrm{a}}$ is a constant representing the maximal amount of oxygen-carrying capacity of a unit volume of blood at a hematoc rit of 0.44 . In a comparison of the calculated $\mathrm{OEF}$ or $\mathrm{CMRO}_{2}$ in young vs aged wild-type mice, no statistical differences were observed. However, $\mathrm{CMRO}_{2}$ was significantly lower in aged arc $A \beta$ mice (vs young). Amyloid plaque deposition and vascular amyloid pathology were widely observed in aged but not young wild-type and arcA $\beta$ mice, indicating that the reduced $\mathrm{CMRO}_{2}$ in the aged arcA $\beta$ mice is not simply the result of aging but is instead related to the advanced amyloid pathology (Figure 3) [46, 47].

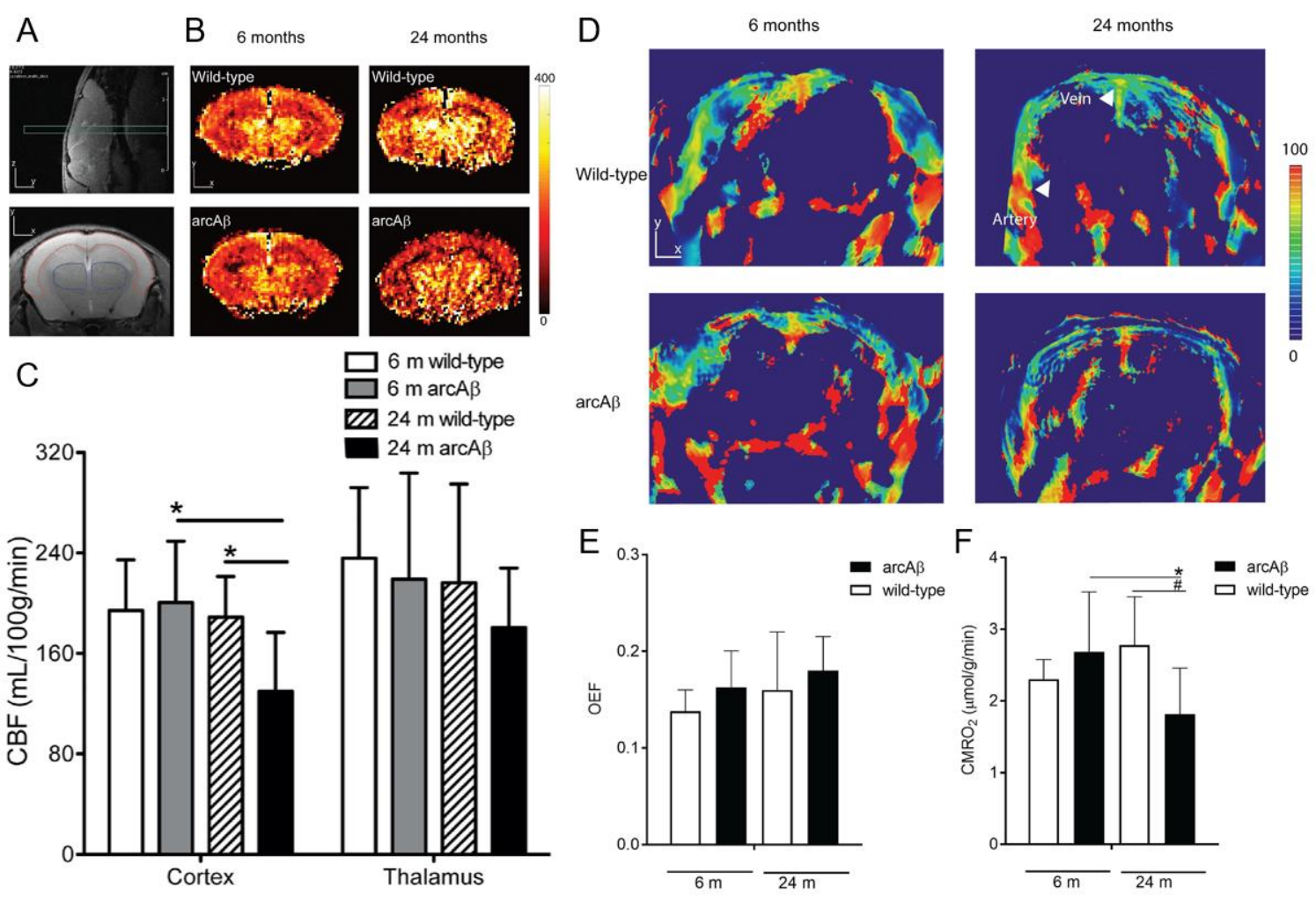

Figure 3 Perfusion MRI and PACT images of young and aged wild-type and $\operatorname{arcA} \beta$ mice. (A) Anatomical position of the coronal plane imaged by perfusion MRI from the sagittal view. Cortex is labeled red and thalamus is labeled blue. (B) Representative coronal cerebral blood flow (CBF) maps. (C) Reduced CBF in cortex is observed in aged $\operatorname{arc} A \beta$ mice compared to aged wild-type mice. (D) Coronal view of $\mathrm{SO}_{2}$ maps. The coronal plane was approximately at Bregma $-1.5 \pm 0.3 \mathrm{~mm}$. White arrow indicates the middle cerebral artery (MCA) and superior sagittal sinus (SSS). (E, F) Quantification of brain oxygen extraction fraction (OEF) and cerebral metabolic rate of oxygen $\left(\mathrm{CMRO}_{2}\right)$. OEF does not significantly differ among the four groups. However, $\mathrm{CMRO}_{2}$ is lower in aged $\operatorname{arc} A \beta$ mice compared to both aged wild-type and young $\operatorname{arc} A \beta$ mice. All statistical results are mean \pm standard deviation with $p<0.05$, one-way ANOVA with post-hoc Bonferroni correction for multiple comparison. (reproduced from [44], Photoacoustics, all rights reserved) 


\section{Photoacoustic Probes for AD}

Recent efforts have been made to identify probes that can be used in PAl to visualize AD. Park et al. have demonstrated the application of the CDnir7 probe in multispectral PACT imaging of $A D$ mouse brain [48]. CDnir7 was previously developed to target macrophages and used to image mouse inflammation with IVIS imaging and fluorescence molecular tomography (FMT) [49]. The accumulation of microglia and macrophages induces chronic inflammation, which occurs before visible symptoms of $A D$ such as $A \beta$ plaque formation, progress cognitive decline, and irreversible memory loss [50]. Therefore, CDnir7 probes were used to target inflammation regions in the brain and distinguish $A D$ brain from healthy brain. CDnir7 was injected through the tail veins of five $A D$ mice (13- and15-mo old). PA images were acquired at five wavelengths $(715,730,760,800$, and $850 \mathrm{~nm}$ ), and the reconstructed images were linearly unmixed on a per-pixel base to differentiate the spectral signature of $\mathrm{CDnir} 7, \mathrm{HbO}_{2}$, and $\mathrm{HbR}$. Compared to healthy brain, $\mathrm{AD}$ brain exhibited higher intensities at the cortex from 20 min post-injection onward and reached a maximum AD-tocontrol difference at 30 min post-injection (Figure 4). However, the CDnir7 photoacoustic signal remained at the same intensity at the SSS for both healthy and AD brains within the first hour postinjection. In addition, the PA signal of total hemoglobin in the cortex region remained higher in the healthy brain (vs AD brain) within $1 \mathrm{~h}$ post-injection. This experiment confirmed the high specificity of CDnir7 for targeting cortical regions in the $A D$ brain and its potential to distinguish $A D$ brains from healthy brains in clinical settings.

A

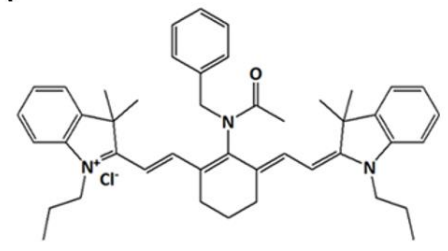

CDnir7

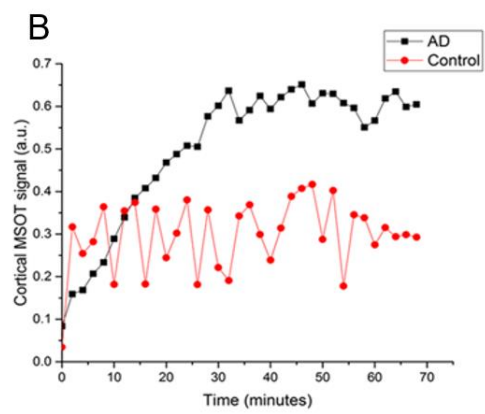

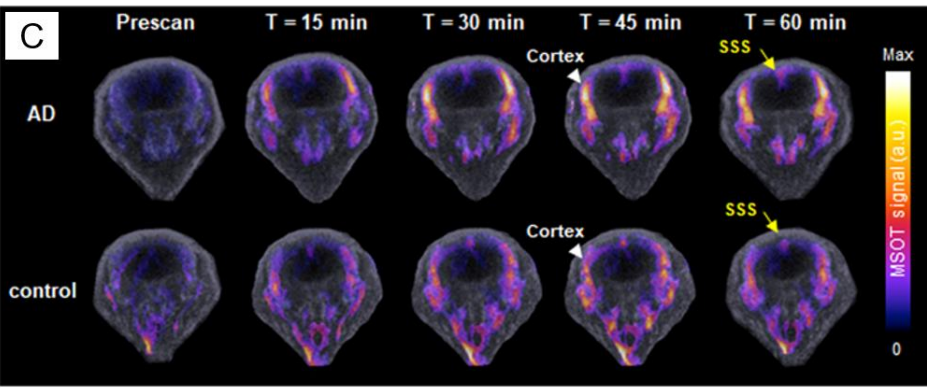

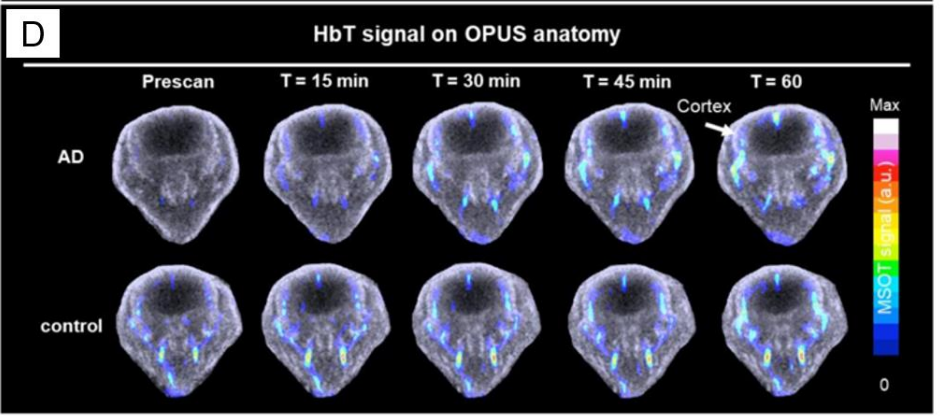

Figure 4 PAI of CDnir7 localization in the mouse brain. (A) Chemical structure of CDnir7. (B) PA signal of CDnir7 at various time points for both $A D$ and healthy brain. (C) PA signal of CDnir7 in the cortex of both $A D$ and healthy brain as a function of time. From 20 min post-injection onward, a stronger PA signal was observed in the cortex of $A D$ brain. In contrast, the PA signal at SSS remained similar in both $A D$ and healthy brain during the entire experiment. (D) PA signal of total hemoglobin in $A D$ and healthy brain. No high signals in the cortex area in AD brain were observed during the course of the experiment. (reproduced from [48], Scientific Reports, all rights reserved) 
Instead of using existing dyes that are designed for fluorescence imaging, Wang et al. have developed an activatable PA probe for the visualization of $\mathrm{Cu}^{2+}$ in AD mice [51]. Copper is the third most abundant trace metal in the human body and plays a vital role in both physiological and pathological activity. Studies have shown that, in mouse $A D$ model, the relocation of copper from intracellular to extracellular space and from bound to free pools presents in serum or in $A B$ deposits. The $\mathrm{Cu}^{2+}$ enrichment in the brain is closely related to AD pathogenesis [52]. Based on these pathological events and the structure of $A D$ drugs, an activatable PA probe, RPS1, was designed. The probe has a molecular weight of $\angle 438 \mathrm{Da}$ and can effectively cross the blood-brainbarrier (BBB) with specific near-infrared (NIR) PA detection (Figure 5A). Upon chelation with $\mathrm{Cu}^{2+}$, the RPS1 probe becomes RPS1-Cu and generates strong PA signals at $710 \mathrm{~nm}$; beyond this wavelength, the PA signal is dampened (Figure 5B). RPS1 was injected via tail vein into both wild-type and AD mice, and the coronal plane of the mouse brain was imaged with PACT at $750 \mathrm{~nm}$ (Figure $5 C$ ). The PA images show that strong signals from the probe were widely distributed across the brain in $A D$ mice with minimal signals observed in healthy brain or AD brain injected with PBS (Figure 5D).
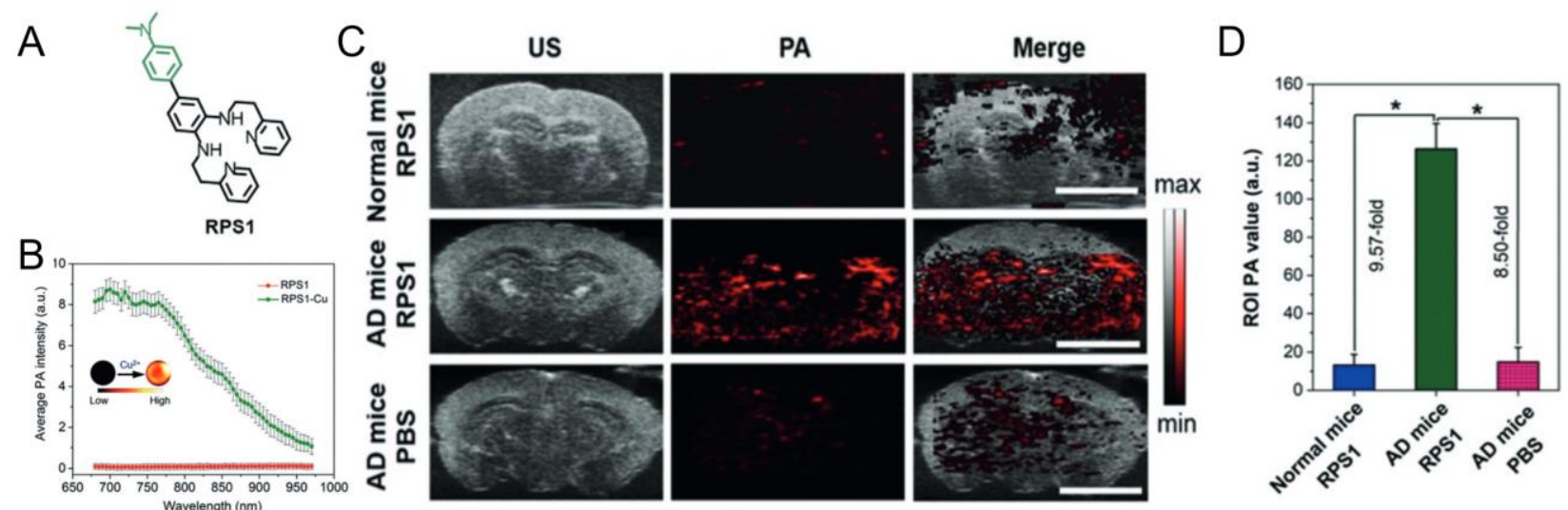

Figure 5 PAI of RPS1 probe in the mouse brain. (A) Chemical structure of RPS1. (B) PA spectra of RPS1 and RPS1-Cu from 680 to $970 \mathrm{~nm}$. The RPS1-Cu has an excitation peak at $710 \mathrm{~nm}$. (C) PA images of $A D$ and healthy mouse brain. The brain images of AD mice show strong PA signals from RPS1 in the cortex region. Weak PA signals observed in normal mice injected with RPS1 and AD mice injected with PBS were likely due to hemoglobin. (D) Within the region of interest, the PA signal from AD mice injected with RPS1 was approximately 9-fold stronger than those of the other two groups. (reproduced from [51], Angewandte Chemie, all rights reserved)

\subsection{Ultrasound Imaging}

Ultrasound (US) imaging derives contrast from the echogenicity and differing mechanical properties of the tissue and can reveal structural information up to tens of centimeters. With specially designed pulse transmission sequence and processing algorithms, US imaging can provide high-resolution in vivo transcranial imaging of rats $[53,54]$. In addition, focused US with microbubble contrast agents has been intensively studied for the opening of the blood-brain barrier (BBB) and may become a promising therapeutic method for AD [55]. 


\subsection{Diagnostic Ultrasound Imaging}

Conventional US imaging has been used for more than 40 years to provide visualization of tissue morphology and blood flow imaging. Due to its low frame rate (up to $50 \mathrm{fps}$ ), the observation of rapid dynamic responses of biological tissues is not feasible. In the last decade, US has gained new capabilities following the implementation of ultrafast plane wave imaging technology (i.e., temporal resolution can approach $10,000 \mathrm{fps}$ ), which enables the visualization of transient shear wave propagation for elasticity imaging [56]. Quantitative assessment of the elastic properties of the brain is relevant in the diagnosis of many neurological diseases, including AD [57]. A pioneer study of in vivo mapping of brain elasticity in small animals has been done by Mace et al., suggesting that this technology can help elucidate the mechanisms of development of neurodegenerative diseases [58]. To improve imaging resolution, Lay et al. recently characterized brain elasticity in age-related mice model using high frequency (40 MHz) ultrasound elastography (HFUSE) [59]. In a study of mice brains aged 4 - 11 months, a softer elastic modulus was observed in both cortex and hippocampus in the older mice (Figure 6). Within the same age group, the significant stiffness difference between hippocampus and cortex is possibly due to their composition - i.e., the concentrations of protein, lipid, and glycosaminoglycan [60]. The stiffness of brain tissue can potentially become another diagnostic parameter of $A D$, as suggested by Murphy et al. Brain tissue of $A D$ patients generally has reduced stiffness, which may be due to microstructural events that destroy normal cytoarchitectural integrity such as degradation of the extracellular matrix due to the deposition of $A \beta$, cytoskeletal disruption due to tau hyperphosphorylation, and the loss of interconnecting synaptic networks $[57,61]$. In addition to the observation of biomechanical changes, the implementation of the plane wave imaging technology can visualize the transient changes in blood volume by orders of magnitude through enhanced Doppler sensitivity and is able to provide functional information in neuroimaging [62, 63].

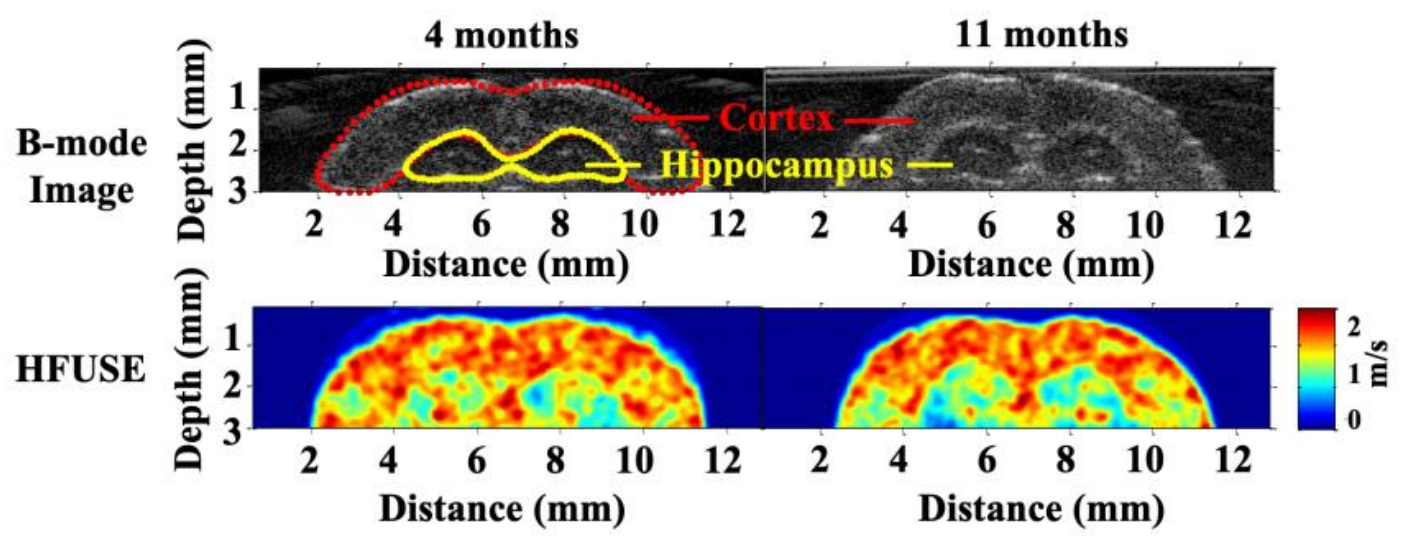

Figure 6 Typical B-mode images and their corresponding high-frequency US elastography (HFUSE) images for 4-month-old and 11-month-old mice. The hippocampus and cortex regions were identified in the B-mode image and are denoted by yellow and red lines, respectively. (reproduced from [59], IEEE, all rights reserved)

Continuous neuronal activity gives rise to functional coupling between different regions of the brain. As neurological and psychiatric diseases involve the disruption of large-scale functional 
changes, an investigation of intrinsic network connectivity is of great interest for better understanding of $A D$. Osmanski et al. launched a pioneer study on mapping the intrinsic connectivity in the living animal with high spatiotemporal resolution using a $15 \mathrm{MHz}$ linear array transducer [64]. To reduce the acoustic attenuation caused by the skull, rat brain imaging was performed with a large thinned-skull imaging window. Based on the cerebral microvascular hemodynamics of the rat brain, functional US imaging is able to provide functional connectivity mapping with unprecedented resolution and sensitivity (Figure 7).
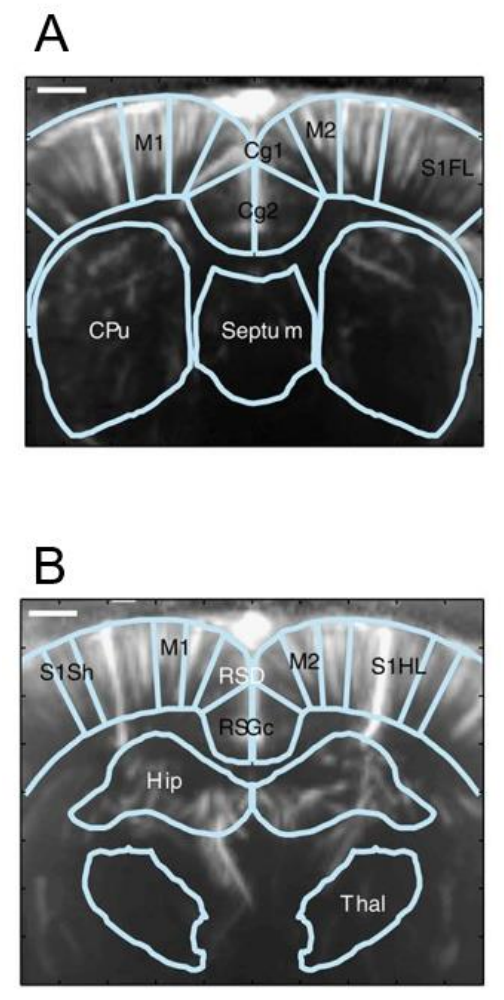
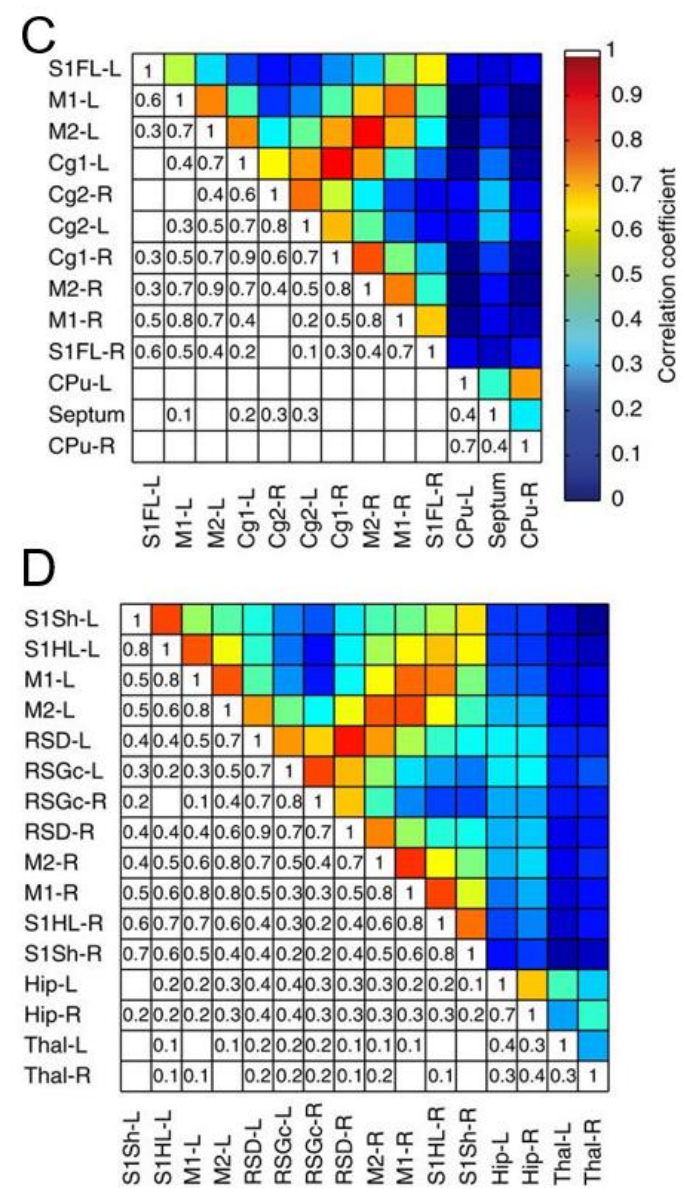

Figure 7 Correlation matrices of the functional connectivity. $(A, C)$ Matrices at Bregma $+0.84 \mathrm{~mm}$ and $(B, D)$ matrices at Bregma $-2.16 \mathrm{~mm}$. (reproduced from [64], NPG group, all rights reserved)

Recent progress on the visualization of brain vasculature in AD mice was achieved by Li et al. using a high-frequency US transducer $(40 \mathrm{MHz})$ to evaluate cerebrovascular density [65]. Without any contrast microbubbles, a spatial resolution of $48 \mu \mathrm{m}$ was achieved, which is the best to date. The results indicate that both cortical and hippocampal vessel densities are similar in young and middle-aged control mice. However, middle-aged mice with $A D$ have a significantly lower vessel density (vs middle-aged, nongenetically-modified WT mice), especially in the hippocampus (Figure 8). It is notable that super-resolution US imaging of microvessels (through the localization of spatially isolated microbubbles and formation of fine-scale brain vascular network) will advance functional neuroimaging even further [53]. 


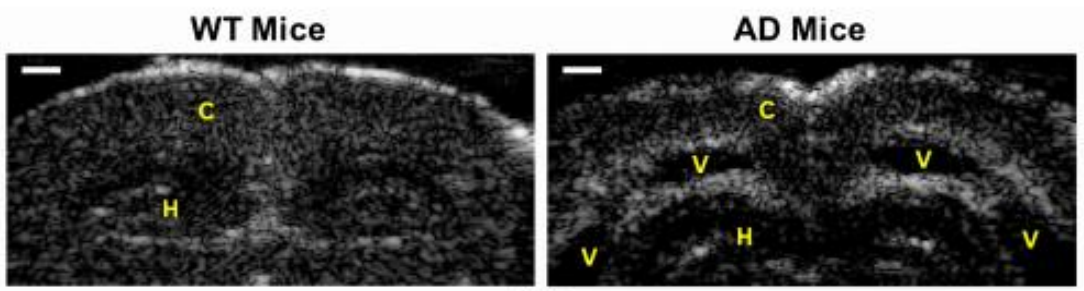

(a)
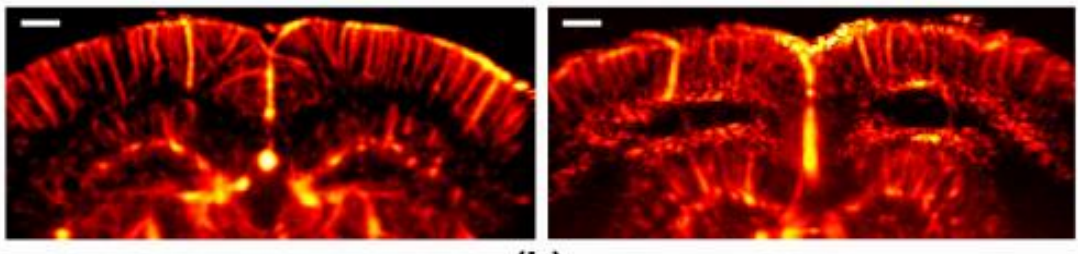

(b)
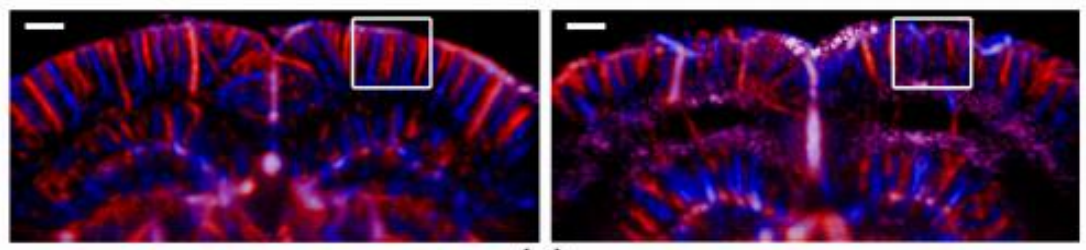

(c)

Figure 8 A comparis on of vessel density between control WT mice and AD mice. (A) B mode structure of the brain. The image size is $3 \mathrm{~mm} \times 7 \mathrm{~mm}$. (B) The corresponding power Doppler image. (C) Directional flow images. (reproduced from [65], IEEE, all rights reserved)

\subsection{Therapeutic Ultrasound}

US imaging is not only useful as a diagnostic modality but may also represent a therapeutic avenue. Several labs have studied the application of focused ultrasound to open the BBB in the treatment of Alzheimer's-related plaques. Jordan et al. were the first to report the delivery of anti$A \beta$ antibodies (e.g., BAM-10) to the AD mouse brain using MRI-guided transcranial focused US [66]. The interaction of burst low-frequency US exposure $(0.558 \mathrm{MHz}$ center frequency, $10 \mathrm{~ms}$ bursts/ $\mathrm{Hz}, 120 \mathrm{~s}, 0.3 \mathrm{MPa}$ ) with injected microbubbles results in transient disruption of the BBB. The extent of disruption of the BBB was monitored with 3.0T MRI. BAM-10 bound to plaques very quickly and remained associated with plaques for at least four days. These results highlight that a single US treatment with low-dose antibodies can successfully reduce the pathology of compact plaques.

Leinenga et al. used a focused US strategy to remove plaque without the need for a therapeutic agent such as an anti-A $\beta$ antibody (Figure 9) [67]. In their study, a relatively short scanning US was implemented. Specifically, US waves were delivered using a $1 \mathrm{MHz}$ transducer under a $0.7 \mathrm{MPa}$ peak rarefactional pressure with a $10 \mathrm{~Hz}$ pulse repetition frequency, $10 \%$ duty cycle, and $6-\mathrm{s}$ sonication time per spot. As a result, compared to sham-treated mice, $75 \%$ of ultrasound-treated $A D$ mice had a reduced plaque burden. In addition, US-treated mice exhibited improved performance for three memory tasks: the Y-maze, the novel object recognition test, and the active place avoidance task. Building upon the preclinical data that suggested the feasibility of focused US to reduce $A \beta$ and tau phosphorylation with subsequent improvements in cognition, Lipsman et al. successfully applied MR-guided focused US in combination with intravenously injected 
microbubbles to open a focal area of the BBB in five early or moderate AD patients [68]. In their study, the focused US had a center frequency of $220 \mathrm{kHz}$, burst duration of $300 \mathrm{~ms}$ (duty cycle: $0.74 \%)$, and burst interval of $2.7 \mathrm{~s}$. These studies suggest that low-frequency, low-power, focused US waves can serve as an early-stage, non-invasive, therapeutic technology to reduce the number of plaques and potentially improve cognition in $A D$ patients. The precise and accurate localization of ultrasonic energy to deep subcortical and cortical targets of $A D$ brains, without damage to surrounding normal tissues, still needs future investigation.

A

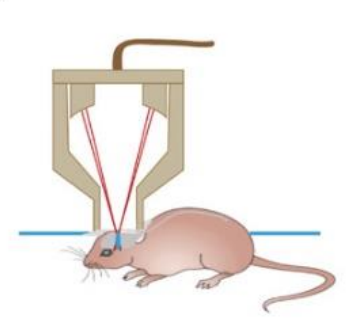

B

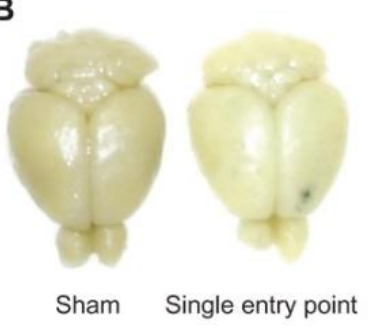

C

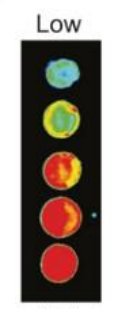

High

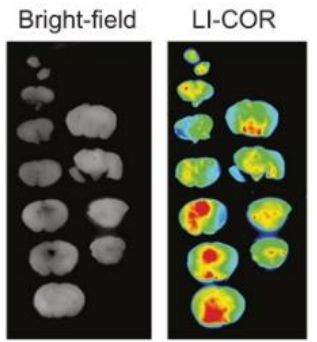

SUS

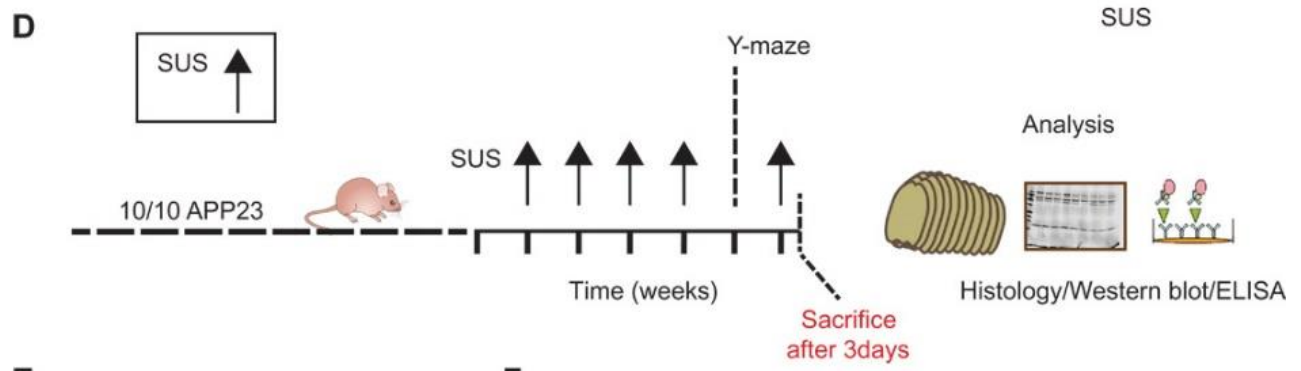

E

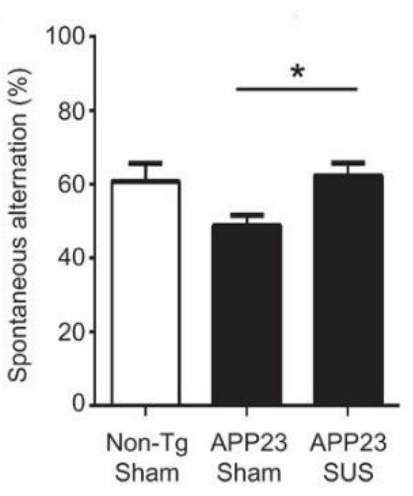

$\mathbf{F}$

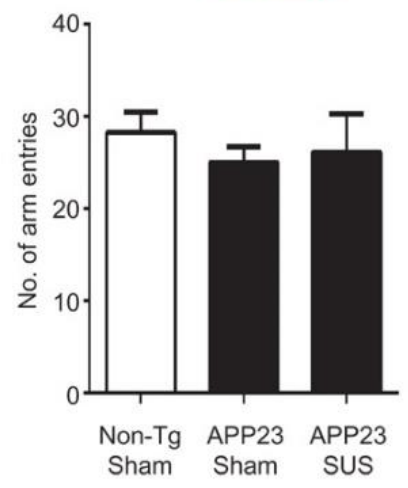

Figure 9 Establishing repeated scanning ultrasound (SUS) in an AD mouse model. (A) Simplified system schematics. (B) Evans blue dye was injected as an indicator. In response to US treatment, the single-entry point reveals a focal opening of the BBB. (C) Odyssey fluorescence LI-COR scan of brain slices, showing widespread opening of the BBB 1 hour after SUS. (D) Simplified schematic for treatment and analysis. (E) The sequence of arm entries in the Y-maze was used to obtain a measure of alternation, reflecting spatial working memory. US treated mice exhibited improved performance for three memory tasks: the Y-maze, the novel object recognition test, and the active place avoidance task. (F) Total number of arm entries did not differ between groups. (reproduced from [67], AAAS, all rights reserved)

In addition to the aforementioned therapeutic capabilities of focused US, intensity focused US has rapidly gained momentum on neuromodulating, including modulating regional brain activities 
and promoting the neurogenesis [69-71]. There is increasing evidence to support a close relationship between the common symptoms of $A D$ (cognitive deficits, difficulty learning, and memory loss) and impairment neurogenesis [72]. In 2014, Scarcelli et al. hypothesized that focused US targeting the hippocampus could stimulate neurogenesis [73]. Although the mechanisms of focused US-induced hippocampal neurogenesis have not been fully elucidated, the experimental results have demonstrated improved behavior in $A D$ mice following treatment. As a new method for non-invasive brain stimulation, US-based brain stimulation for treating $A D$ is a very active research area.

\section{Conclusion \& Discussion}

In this concise review, we summarized recent developments in PA and US imaging for AD research. PA imaging has shown great potential for detecting $A D$ either through direct imaging of labeled $A \beta$ or by monitoring of physiological parameters such as cerebral blood oxygenation and brain oxygen extraction fraction. A va riety of contrast agents, including CDnir7 and R PS1, have also been explored to target different biomarkers potentially correlated with $A D[42,48,51]$. US imaging has value not only as a diagnostic tool for functional brain imaging but also as a therapeutic tool for drug delivery and plaque reduction. Cerebral microvascular hemodynamics can be readily measured by functional US imaging with a high spatiotemporal resolution, and brain elasticities have been characterized in several animal models $[59,65,66]$. In addition to its diagnostic abilities, focus ed US waves in combination with microbubbles can facilitate BBB opening and the subsequent delivery of drugs that target $A D$-related plaques.

More importantly, as both modalities detect acoustic signals, PA imaging is inherently compatible with US imaging and can be readily incorporated into commercial US systems. While US imaging generally provides structural information, PA imaging readily provides high-contrast functional and molecular information. Many studies have been done using combined PA and US imaging for cancer detection and surgical guidance [74-81]. Some recent work also combines PA and US imaging for brain imaging and therapeutic guidance. Wang et al. quantitatively monitored fUS-induced BBB opening in a rat model in vivo with PAM and gold nanorods as the PA contrast agent [82]. The PAM images can successfully reveal the spatial distribution and temporal response of the BBB disruption area. Similarly, Hartman et al. used PA imaging to image gold nanorods in the brain delivered via microbubble-assisted fUS [83]. Multifunctional contrast agents for PA and US imaging, such as encapsulated-ink poly(lactic-coglycolic acid) microbubbles and nanobubbles, methylene blue microbubbles, and copper sulfide nanoparticles, have been developed [84-86]. A combined PA and US imaging system can provide a highly comprehensive picture of the structures and functions of the $A D$ brain and therefore enable improved diagnostics and treatments for $A D$ patients.

Nevertheless, the skull persists as one of the major challenges for transcranial PA and US imaging of deep brain due to its aberration and attenuation on acoustic waves. Several solutions to overcome the skull's obstacles have already been explored for both small animal and human brain imaging. In small animal transcranial imaging, an animal's skull was removed before acute experiments [63]. For chronic imaging, the skull was either thinned or replaced by an acoustic window made of a high ultrasonic transmission material such as polymethylpentene $[54,87,88]$. Non-invasive small animal US imaging can be achieved with the skull intact if the animal is young 
(before $35^{\text {th }}$ postnatal day) or with an US contrast agent such as microbubbles [70]. For human preclinical applications, US imaging has proved its ability to provide deep, functional cortical mapping during craniotomy (e.g., glioma surgery). Natural anatomic windows such as temporal windows have been utilized for non-invasive US imaging of adult brains. For neonates specifically, the fontanel window has been used for US imaging [89-91]. For transcranial therapy, CT was used to determine the shape and location of the skull for correcting the US aberration [92].

The aforementioned solutions can be applied to US and PA imaging to address the skull's attenuation and aberration of acoustic waves, but PAl faces an addition major challenge: light delivery to the deep target. PA imaging relies on pulsed illumination of the target; because the brain has strong optical scattering, this results in insufficient optical fluence delivered to the deep brain [93, 94]. NIR wavelengths have been used to improve the penetration depth for in vivo imaging of animal brains, but the depth is still limited to millimeters. At longer wavelengths such as in mid-IR, the water absorption is no longer negligible. Contrast agents with high absorption coefficients in the NIR window have been reported, and most of them are only usable for PA imaging at 700-1000 nm [95-97]. Kim et al. labeled stem cells with Prussian blue nanoparticles, which are an emerging PA contrast agent with strong absorption at $750 \mathrm{~nm}$ [98]. This method can potentially be used for PA imaging of AD brain, as the labeled stem cells were successfully injected into living mouse brain and monitored for 14 days with in vivo cell tracking. Low image quality due to limited light fluence delivery can also be solved by using more advanced reconstruction methods. Mozaffarzadeh et al. have shown that a double-stage, delay-multiply-and-sum reconstruction algorithm can greatly enhance the lateral resolution and contrast ratio under low fluence excitation provided by LED [99]. In summary, although challenges such as optical attenuation and transcranial US aberration remain, transcranial PA/US imaging is not beyond reach and can potentially generate a profound impact on both AD research and clinical practice.

\section{Acknowledgments}

This work was supported in part by National Institute of Health (R01 EB028143, R01 NS111039, R01 NS115581, R21 EB027304, R43 CA243822, R43 CA239830, R44 HL138185); Duke MEDx Basic Science Grant; Duke Center for Genomic and Computational Biology Faculty Research Grant; Duke Institute of Brain Science Incubator Award; and American Heart Association Collaborative Sciences Award (18CSA34080277). The authors thank Caroline Connor for editing the manuscript.

\section{Author Contributions}

Y.T., X.Q., Q.Z. and J.Y. designed the study and wrote the manuscript. All authors contributed to manuscript revision and discussion.

\section{Competing Interests}

The authors have declared that no competing interests exist.

\section{References}

1. Alzheimer's Association. 2019 Alzheimer's disease facts and figures. Alzheimers Dement. 2019; 15: 321-387. 
2. Selkoe DJ. Amyloid $\beta$ protein precursor and the pathogenesis of Alzheimer's disease. Cell. 1989; 58: 611-612.

3. Braak H, Braak E. Neuropathological stageing of Alzheimer-related changes. Acta Neuropathol. 1991; 82: 239-259.

4. Alzheimer A. About a peculiar disease of the cerebral cortex. Centralbl Nervenheilkunde Psychiat. 1907; 30: 177-179.

5. Selkoe DJ. Alzheimer's disease: Genes, proteins, and therapy. Physiol Rev. 2001; 81: 741-766.

6. Perl DP. Neuropathology of Alzheimer's disease. Mt Sinai J Med. 2010; 77: 32-42.

7. Jack CR, Knopman DS, Jagust WJ, Petersen RC, Weiner MW, Aisen PS, et al. Tracking pathophysiological processes in Alzheimer's disease: An updated hypothetical model of dynamic biomarkers. Lancet Neurol. 2013; 12: 207-216.

8. Dubois B, Feldman HH, Jacova C, Cummings JL, DeKosky ST, Barberger-Gateau P, et al. Revising the definition of Alzheimer's disease: A new lexicon. Lancet Neurol. 2010; 9: 11181127.

9. Denver P, McClean PL. Distinguishing normal brain aging from the development of Alzheimer's disease: Inflammation, insulin signaling and cognition. Neural Regen Res. 2018; 13: 1719.

10. Rajput A H, Rozdilsky B, Rajput A. Alzheimer's disease and idiopathic Parkinson's disease coexistence. J Geriatr Psych Neur. 1993; 6: 170-176.

11. Jezzard P, Matthews PM, Smith SM. Functional MRI: An introduction to methods. Oxford: Oxford university press. 2001.

12. Arthurs OJ, Boniface S. How well do we understand the neural origins of the fMRI BOLD signal? Trends Neurosci. 2002; 25: 27-31.

13. Posse $S$, Ackley E, Mutihac R, Zhang T, Hummatov R, Akhtari M, et al. High-speed real-time resting-state $\mathrm{fMRI}$ using multi-slab echo-volumar imaging. Front Human Neurosci. 2013; 7 : 479.

14. Liu Y, Wang K, Yu C, He Y, Zhou Y, Liang M, et al. Regional homogeneity, functional connectivity and imaging markers of Alzheimer's disease: A review of resting-state fMRI studies. Neuropsychologia. 2008; 46: 1648-1656.

15. Rocher AB, Chapon F, Blaizot X, Baron JC, Chavoix C. Resting-state brain glucose utilization as measured by PET is directly related to regional synaptophysin levels: A study in baboons. Neuroimage. 2003; 20: 1894-1898.

16. Pellerin L, Magistretti PJ. Glutamate uptake into astrocytes stimulates aerobic glycolysis: A mechanism coupling neuronal activity to glucose utilization. Proc Natl Acad Sci USA. 1994; 91 : 10625-10629.

17. Silverman DH, Small GW, Chang CY, Lu CS, Kung De Aburto MA, Chen W, et al. Positron emission tomography in evaluation of dementia: Regional brain metabolism and long-term outcome. JAMA. 2001; 286: 2120-2127.

18. Foster NL, Heidebrink JL, Clark CM, Jagust WJ, Arnold SE, Barbas NR, et al. FDG-PET improves accuracy in distinguishing frontote mporal dementia and Alzheimer's disease. Brain. 2007; 130: 2616-2635.

19. Klunk WE, Engler H, Nordberg A, Wang Y, Blomqvist G, Holt DP, et al. Imaging brain amyloid in Alzheimer's disease with Pittsburgh Compound-B. Ann Neurol. 2004; 55: 306-319. 
20. Humbert $O$, Lasserre $M$, Bertaut A, Fumoleau $P$, Coutant $C$, Brunotte $F$, et al. Breast cancer blood flow and metabolism on dual-acquisition 18F-FDG PET: Correlation with tumor phenotype and neoadjuvant chemotherapy response. J Nucl Med. 2018; 59: 1035-1041.

21. Buck AK, Herrmann K, Stargardt T, Dechow T, Krause BJ, Schreyögg J. Economic evaluation of PET and PET/CT in oncology: Evidence and methodologic approaches. J Nucl Med Technol. 2010; 38: 6-17.

22. Kromer R, Serbecic N, Hausner L, Aboul-Enein F, Froelich L, Beutelspacher S. Detection of retinal nerve fiber layer defects in Alzheimer's disease using SD-OCT. Front Psychiatry. 2014; 5: 22.

23. Cunha LP, Almeida ALM, Costa-Cunha LVF, Costa CF, Monteiro MLR. The role of optical coherence tomography in Alzheimer's disease. Int J Retin Vitr. 2016; 2: 1-11.

24. Kim D, Baik SH, Kang S, Cho SW, Bae J, Cha MY, et al. Close correlation of monoamine oxidase activity with progress of Alzheimer's disease in mice, observed by in vivo two-photon imaging. ACS Cent Sci. 2016; 2: 967-975.

25. Liebscher S, Meyer-Luehmann M. A peephole into the brain: Neuropathological features of Alzheimer's disease revealed by in vivo two-photon imaging. Front Psychiatry. 2012; 3: 26.

26. Beard P. Biomedical photoacoustic imaging. Interface Focus. 2011; 1: 602-631.

27. Wang LV, Gao L. Photoacoustic microscopy and computed tomography: From bench to bedside. Ann Rev Biomed Eng. 2014; 16: 155-185

28. Hu S, Wang LV. Neurovascular photoacoustic tomography. Front Neuroenerget. 2010; 2: 10.

29. Xia J, Yao J, Wang LV. Photoacoustic tomography: Principles and advances. Electromagn Waves (Camb). 2014; 147: 1-22.

30. Wang LV. Multiscale photoacoustic microscopy and computed tomography. Nat Photonics. 2009; 3: 503-509.

31. Yao J, Wang LV. Photoacoustic microscopy. Laser Photonics Rev. 2013; 7: 758-778.

32. Wang LV, Wu H. Biomedical optics: Principles and imaging. John Wiley \& Sons. 2012.

33. Cox B, Laufer JG, Arridge SR, Beard PC. Quantitative spectroscopic photoacoustic imaging: A review. J Biomed Opt. 2012; 17: 061202.

34. Zhang P, Li L, Lin L, Hu P, Shi J, He Y, et al. High-resolution deep functional imaging of the whole mouse brain by photoacoustic computed tomography in vivo. J Biophotonics. 2018; 11: e201700024.

35. Lin L, Xia J, Wong TTW, Li L, Wang LV. In vivo deep brain imaging of rats using oral-cavity illuminated photoacoustic computed tomography. J Biomed Opt. 2015; 20: 016019.

36. Li L, Xia J, Li G, Garcia-Uribe A, Sheng Q, Anastasio MA, et al. Label-free photoacoustic tomography of whole mouse brain structures ex vivo. Neurophotonics. 2016; 3: 035001.

37. Wang LV, Yao J. A practical guide to photoacoustic tomography in the life sciences. Nat Methods. 2016; 13: 627-638.

38. Li M, Tang $Y$, Yao J. Photoacoustic tomography of blood oxygenation: A mini review. Photoacoustics. 2018; 10: 65-73.

39. Harrop Jr GA. The oxygen and carbon dioxide content of arterial and of venous blood in normal individuals and in patients with anemia and heart disease. J Exp Med. 1919; 30: 241.

40. Ogawa $S$, Lee TM, Kay AR, Tank DW. Brain magnetic resonance imaging with contrast dependent on blood oxygenation. PNAS. 1990; 87: 9868-9872. 
41. Menon RS, Kim SG. Spatial and temporal limits in cognitive neuroimaging with fMRI. Trends Cogn Sci. 1999; 3: 207-216.

42. Hu S, Yan P, Maslov K, Lee JM, Wang LV. Intravital imaging of amyloid plaques in a transgenic mouse model using optical-resolution photoacoustic microscopy. Opt Lett. 2009; 34: 38993901.

43. Scott Prahl. Optical Absorption of Hemoglobin [Internet]. 2019. Available from: https://omlc.org/spectra/hemoglobin/

44. Ni R, Rudin M, Klohs J. Cortical hypoperfusion and reduced cerebral metabolic rate of oxygen in the arcA $\beta$ mouse model of Alzheimer's disease. Photoacoustics. 2018; 10: 38-47.

45. Clarke DD, Sokoloff L. Circulation and energy metabolism of the brain. Basic Neurochemistry: Molecular, Cellular and Medical Aspects. 1999.

46. Klohs J, Politano IW, Deistung A, Grandjean J, Drewek A, Dominietto M, et al. Longitudinal assessment of amyloid pathology in transgenic $\operatorname{Arc} A \beta$ mice using multi-parametric magnetic resonance imaging. PLoS One. 2013; 8: e66097.

47. Knobloch $M$, Fa rinelli $M$, Konietzko $U$, Nitsch RM, Mansuy IM. A $\beta$ oligomer-mediated longterm potentiation impairment involves protein phosphatase 1-dependent mechanisms. J Neurosci. 2007; 27: 7648-7653.

48. Park SJ, Ho CJH, Arai S, Samanta A, Olivo M, Chang YT. Visualizing Alzheimer's disease mouse brain with multispectral optoacoustic tomography using a fluorescent probe, CDnir7. Sci Rep. 2019; 9: 1-8.

49. Fernández A, Vendrell M. Smart fluorescent probes for imaging macrophage activity. Chem Soc Rev. 2016; 45: 1182-1196.

50. Lian $H$, Litvinchuk A, Chiang ACA, Aithmitti N, Jankowsky JL, Zheng H. Astrocyte-microglia cross talk through complement activation modulates amyloid pathology in mouse models of Alzheimer's disease. J Neurosci. 2016; 36: 577-589.

51. Wang S, Sheng Z, Yang Z, Hu D, Long X, Feng G, et al. Activatable small-molecule photoacoustic probes that cross the blood-brain barrier for visualization of copper(II) in mice with Alzheimer's disease. Angew Chem Int Edit. 2019; 58: 12415-12419.

52. Kepp KP. Bioinorganic chemistry of Alzheimer's disease. Chem Rev. 2012; 112: 5193-5239.

53. Errico C, Pierre J, Pezet S, Desailly Y, Lenkei Z, Couture O, et al. Ultrafast ultrasound localization microscopy for deep super-resolution vascular imaging. Nature. 2015; 527: 499502.

54. Errico C, Osmanski BF, Pezet S, Couture O, Lenkei Z, Tanter M. Transcranial functional ultrasound imaging of the brain using microbubble-enhanced ultrasensitive Doppler. Neurolmage. 2016; 124: 752-761.

55. Silva ICS, Delgado ABT, Silva PHVD, Costa VRX. Focused ultrasound and Alzheimer's disease A systematic review. Dement Neuropsychol. 2018; 12: 353-359.

56. Montaldo G, Tanter M, Bercoff J, Benech N, Fink M. Coherent plane-wave compounding for very high frame rate ultrasonography and transient elastography. IEEE Trans Ultrason Ferroelectr Freq Control. 2009; 56: 489-506.

57. Murphy MC, Huston J, Jack CR, Glaser KJ, Manduca A, Felmlee JP, et al. Decreased brain stiffness in Alzheimer's disease determined by magnetic resonance elastography. J Magn Reson Imaging. 2011; 34: 494-498. 
58. Mace E, Cohen I, Montaldo G, Miles R, Fink M, Tanter M. In vivo mapping of brain elasticity in small animals using shear wave imaging. IEEE Trans Med Imaging. 2011; 30: 550-558.

59. Lay $F$, Chen $P$, Cheng $H$, Kuo $Y$, Huang $C$. Ex vivo evaluation of mouse brain elasticity using high-frequency ultrasound elastography. IEEE Trans Biomed Eng. 2019; 66: 3426-3435.

60. Elkin BS, llankovan A, Morrison B. Age-dependent regional mechanical properties of the rat hippocampus and cortex. J Biomech Eng. 2010; 132: 011010.

61. Murphy MC, Jones DT, Jack CR, Glaser KJ, Senjem ML, Manduca A, et al. Regional brain stiffness changes across the Alzheimer's disease spectrum. Neurolmage Clin. 2016; 10: 283290.

62. Deffieux T, Demene $C$, Pernot M, Tanter M. Functional ultrasound neuroimaging: A review of the preclinical and clinical state of the art. Curr Opinion Neurobiol. 2018; 50: 128-135.

63. Macé E, Montaldo G, Cohen I, Baulac M, Fink M, Tanter M. Functional ultrasound imaging of the brain. Nat Methods. 2011; 8: 662-664.

64. Osmanski BF, Pezet S, Ricobaraza A, Lenkei Z, Tanter M. Functional ultrasound imaging of intrinsic connectivity in the living rat brain with high spatiote mporal resolution. Nat Commun. 2014; 5: 1-14.

65. Li $H$, Chen $P$, Cheng $H$, Kuo $Y$, Huang $C$. In vivo visualization of brain vasculature in Alzheimer's disease mice by high-frequency micro-doppler imaging. IEEE Trans Biomed Eng. 2019; 66: 3393-3340.

66. Jordão JF, Ayala-Grosso CA, Markham K, Huang Y, Chopra R, McLaurin J, et al. Antibodies targeted to the brain with image-guided focused ultrasound reduces amyloid- $\beta$ plaque load in the TgCRND8 mouse model of Alzheimer's disease. PLoS One. 2010; 5: e10549.

67. Leinenga G, Götz J. Scanning ultrasound removes amyloid- $\beta$ and restores memory in an Alzheimer's disease mouse model. Sci Trans Med. 2015; 7: 278ra33.

68. Lipsman N, Meng Y, Bethune AJ, Huang Y, Lam B, Masellis M, et al. Blood-brain barrier opening in Alzheimer's disease using MR-guided focused ultrasound. Nat Commun. 2018; 9: 1-8.

69. Tufail Y, Matyushov A, Baldwin N, Tauchmann ML, Georges J, Yoshihiro A, et al. Transcranial pulsed ultrasound stimulates intact brain circuits. Neuron. 2010; 66: 681-694.

70. Lee W, Croce P, Margolin RW, Cammalleri A, Yoon K, Yoo SS. Transcranial focused ultrasound stimulation of motor cortical areas in freely-moving awake rats. BMC Neurosci. 2018; 19: 57.

71. Jin K, Zhu Y, Sun Y, Mao XO, Xie L, Greenberg DA. Vascular endothelial growth factor (VEGF) stimulates neurogenesis in vitro and in vivo. Proc Natl Acad Sci USA. 2002; 99: 11946-11950.

72. Hollands C, Bartolotti N, Lazarov O. Alzheimer's disease and hippocampal adult ne urogenesis; exploring shared mechanisms. Front Neurosci. 2016, 10: 178.

73. Scarcelli T, Jordão JF, O’Reilly MA, Ellens N, Hynynen K, Aubert I. Stimulation of hippocampal neurogenesis by transcranial focused ultrasound and microbubbles in adult mice. Brain Stimul. 2014; 7: 304-307.

74. Kolkman RGM, Brands PJ, Steenbergen W, Leeuwen TGC van. Real-time in vivo photoacoustic and ultrasound imaging. JBO. 2008; 13: 050510.

75. Homan K, Shah J, Gomez S, Gensler H, Karpiouk A, Brannon-Peppas L, et al. Combined ultrasound and photoacoustic imaging of pancreatic cancer using nanocage contrast agents. In: Photons Plus Ultrasound: Imaging and Sensing 2009. Int Soc Opt Photonics. 2009; 7177: 71771M. 
76. Daoudi K, Van Den Berg PJ, Rabot O, Kohl A, Tisserand S, Brands P, et al. Handheld probe integrating laser diode and ultrasound transducer array for ultrasound/photoacoustic dual modality imaging. Opt Express. 2014; 22: 26365-26374.

77. Kang J, Chang JH, Kim SM, Lee HJ, Kim H, Wilson BC, et al. Real-time sentinel lymph node biopsy guidance using combined ultrasound, photoacoustic, fluorescence imaging: In vivo proof-of-principle and validation with nodal obstruction. Sci Rep. 2017; 7: 1-9.

78. Erpelding TN, Kim C, Pramanik M, Jankovic L, Maslov K, Guo Z, et al. Sentinel lymph nodes in the rat: Noninvasive photoacoustic and US imaging with a clinical US system. Radiology. 2010; 256: 102-110.

79. Karpiouk AB, Aglyamov SR, Mallidi S, Shah J, Scott WG, Rubin JM, et al. Combined ultrasound and photoacoustic imaging to detect and stage deep vein thrombosis: Phantom and ex vivo studies. J Biomed Opt. 2008; 13: 054061.

80. Mehrmohammadi M, Joon Yoon S, Yeager DY. Emelianov S. Photoacoustic imaging for cancer detection and staging. Curr Mol Imaging. 2013; 2: 89-105.

81. Harrison T, Ranasinghesagara JC, Lu H, Mathewson K, Walsh A, Zemp RJ. Combined photoacoustic and ultrasound biomicroscopy. Opt Express. 2009; 17: 22041-22046.

82. Wang PH, Li ML, Liu HL, Hsu PH, Lin CY, Wang CRC, et al. Gold-nanorod contrast-enhanced photoacoustic micro-imaging of focused-ultrasound induced blood-brain-barrier opening in a rat model. JBO. 2012; 17: 061222.

83. Hartman RK, Hallam KA, Donnelly EM, Emelianov SY. Photoacoustic imaging of gold nanorods in the brain delivered via microbubble-assisted focused ultrasound: A tool for in vivo molecular neuroimaging. Laser Phys Lett. 2019; 16: 025603.

84. Santiesteban DY, Dumani DS, Profili D, Emelianov SY. Copper sulfide perfluorocarbon nanodroplets as clinically relevant photoacous tic/ultrasound imaging agents. Nano Lett. 2017; 17: 5984-5989.

85. Jeon M, Song W, Huynh E, Kim J, Kim J, Helfield BL, et al. Methylene blue microbubbles as a model dual-modality contrast agent for ultrasound and activatable photoacoustic imaging. JBO. 2014; 19: 016005.

86. Kim C, Qin R, Xu JS, Wang LV, Xu RX. Multifunctional microbubbles and nanobubbles for photoacoustic and ultrasound imaging. JBO. 2010; 15: 010510.

87. Sieu LA, Bergel A, Tiran E, Deffieux T, Pernot M, Gennisson JL, et al. EEG and functional ultrasound imaging in mobile rats. Nat Methods. 2015; 12: 831-834.

88. Urban A, Mace E, Brunner C, Heidmann M, Rossier J, Montaldo G. Chronic assessment of cerebral hemodynamics during rat forepaw electrical stimulation using functional ultrasound imaging. Neuroimage. 2014; 101: 138-149.

89. Imbault M, Chauvet D, Gennisson JL, Capelle L, Tanter M. Intraoperative functional ultrasound imaging of human brain activity. Sci Rep. 2017; 7: 1-7.

90. Demene C, Baranger J, Bernal M, Delanoe C, Auvin S, Biran V, et al. Functional ultrasound imaging of brain activity in human newborns. Sci Trans Med. 2017; 9: eaah6756.

91. Knecht $S$, Deppe $M$, Ebner A, Henningsen $H$, Huber $T$, Jokeit $H$, et al. Noninvasive determination of language lateralization by functional transcranial Doppler sonography: $A$ comparison with the Wada test. Stroke. 1998; 29: 82-86. 
92. Ghanouni P, Pauly KB, Elias WJ, Henderson J, Sheehan J, Monteith S, et al. Transcranial MRIguided focused ultrasound: A review of the technologic and neurologic applications. Am J Roentgenol. 2015; 205: 150-159.

93. Jacques SL. Optical properties of biological tissues: A review. Phys Med Biol. 2013; 58 : R37.

94. Zee $P$ van der, Essenpreis M, Delpy DT. Optical properties of brain tissue. In: photon migration and imaging in random media and tissues. Int Soc Opt Photonics. 1993; 1888: 454-465

95. Wang X, Ku G, Wegiel MA, Bornhop DJ, Stoica G, Wang LV. Noninvasive photoacoustic angiography of animal brains in vivo with near-infrared light and an optical contrast agent. Opt Lett. 2004; 29: 730-732.

96. Pan D, Pramanik M, Senpan A, Ghosh S, Wickline SA, Wang LV, et al. Near infrared photoacoustic detection of sentinel lymph nodes with gold nanobeacons. Biomaterials. 2010; 31: 4088-4093.

97. Filonov GS, Krumholz A, Xia J, Yao J, Wang LV, Verkhusha VV. Deep-tissue photoacoustic tomography of a genetically encoded near-infrared fluorescent probe. Angew Chem Int Edit. 2012; 51: 1448-1451.

98. Kim T, Lemaster JE, Chen F, Li J, Jokerst JV. Photoacoustic imaging of human mesenchymal stem cells labeled with Prussian blue-poly (I-lysine) nanocomplexes. ACS Nano. 2017; 11: 9022-9032.

99. Mozaffarzadeh M, Hariri A, Moore C, Jokerst JV. The double-stage delay-multiply-and-sum image reconstruction method improves imaging quality in a LED-based photoacoustic array scanner. Photoacoustics. 2018; 12: 22-29.

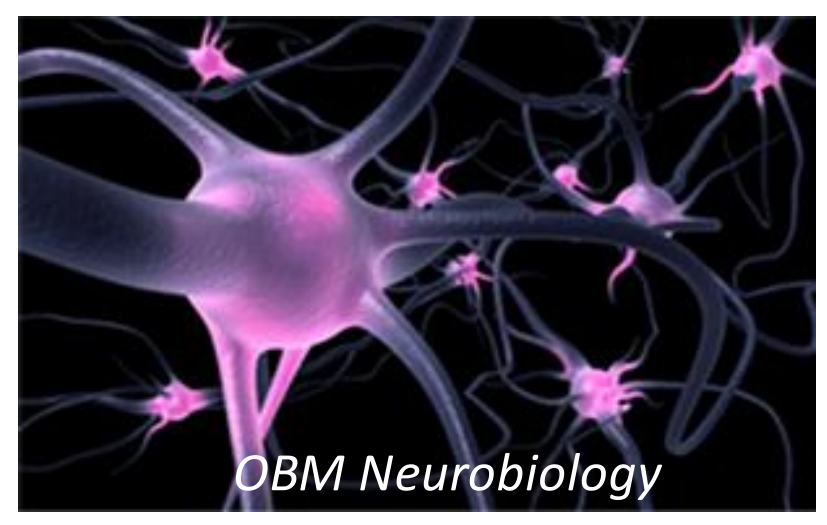

Enjoy OBM Neurobiology by:

1. Submitting a manuscript

2. Joining volunteer reviewer bank

3. Joining Editorial Board

4. Guest editing a special issue

For more details, please visit:

http://www.lidsen.com/journals/neurobiology 